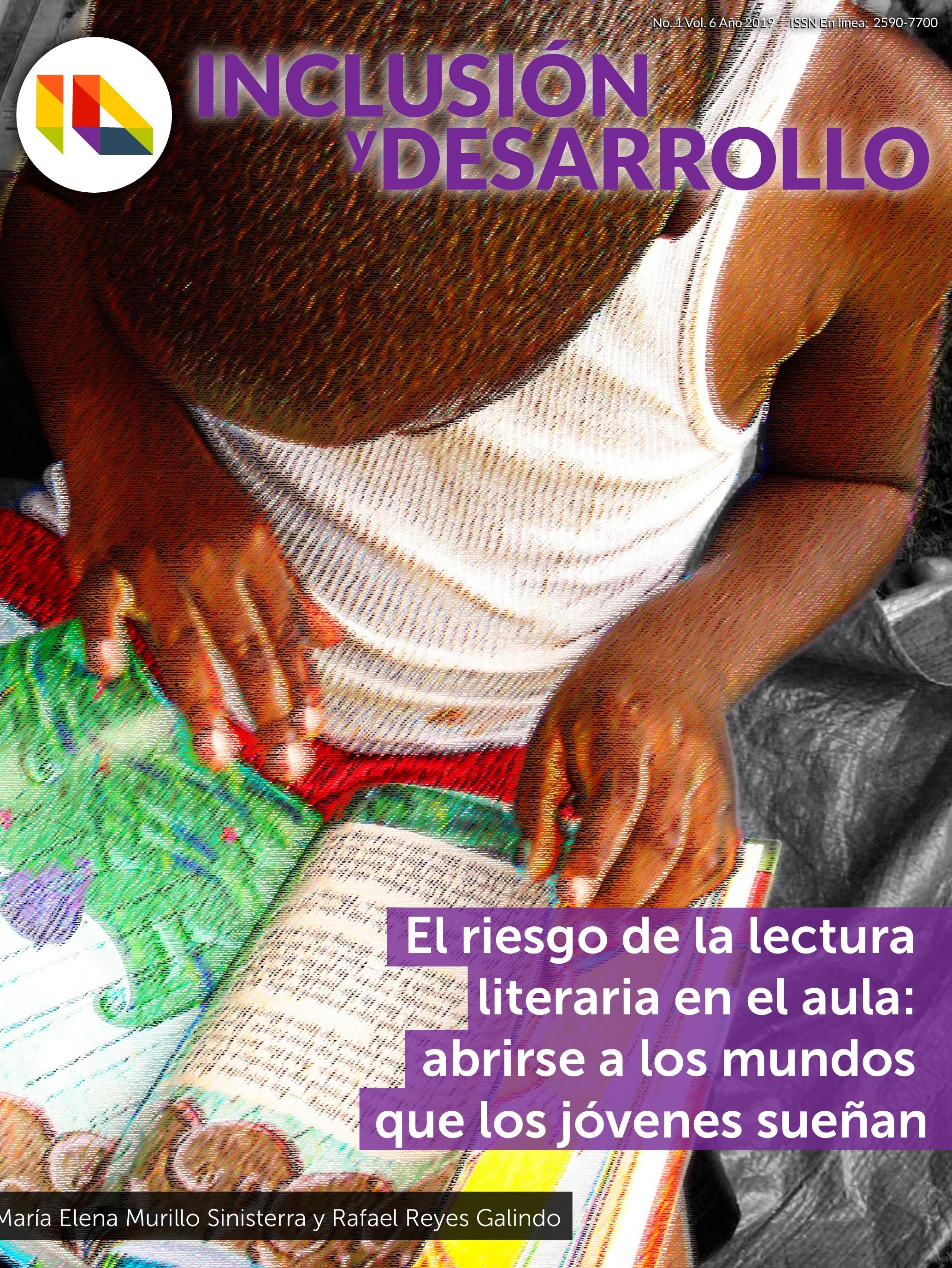




\section{EL RIESGO DE LA LECTURA LITERARIA EN EL AULA: ABRIRSE A LOS MUNDOS QUE LOS JÓVENES SUEÑAN}

\section{THE RISK OF LITERARY READING IN THE CLASSROOM: TO BE WILLING TO KNOW THE WORLDS YOUNG PEOPLE DREAM ABOUT.}

María Elena Murillo Sinisterra murillo.maria@javeriana.edu.co Universidad Javeriana Bogotá D.C. - Colombia

Rafael Reyes Galindo reyes@javeriana.edu.co Universidad Javeriana Bogotá D.C. - Colombia

\section{Resumen}

Este artículo centra su atención en la lectura literaria como subjetividad política. Los sujetos involucrados en este estudio son lectores jóvenes entre dieciséis y veintiún años de la IED La floresta Sur en Bogotá.

Palabras clave: lectura literaria, sujeto, saber pedagógico.

\section{Abstract}

This article focuses on literary reading as political subjectivity. The students involved in this project are young readers between sixteen and twenty-one aged at IED La Floresta in Bogotá.

Keywords: literary Reading, subject, knowledge pedagogy 


\section{¿LA LECTURA COMO ACCESO A LA CULTURA O LA LECTURA COMO RENOVACIÓN DE LA CULTURA?}

Este articulo nace de una pregunta, ¿qué hace Eque los jóvenes lean? Con este fin se emprende una serie de investigaciones en dos campos distintos pero articulados por esta pregunta: en el campo del Semillero de Investigación, Arqueología del Oficio. Saber Pedagógico y formación de Maestros, semillero de la Facultad de Educación de la Pontificia Universidad Javeriana. Y en el trabajo de grado desarrollado para obtener la Licenciatura en Humanidades y Lengua Castellana de la misma Facultad; allí se indaga por la lectura literaria y la forma como afecta la formación de estudiantes de secundaria. Este proceso de formación se entiende como subjetividad política.

Las políticas de la lectura, los mecanismos de su evaluación, las competencias lectoras, las secuencias didácticas de la lectura acentúan, sin confesarlo, que la lectura es obligato-ria. La lectura nos hace cultos, la lectura nos informa. La lectura es condición de acceder a la cultura letrada, de los que saben leer. Pero además de obligatoria la lectura es vista, con frecuencia, como una actividad pasiva: saber leer es identificar las ideas principales, cono-cer el contexto, interpretar al autor, reconocer la coherencia del texto, apreciar su cohe-sión. Pero ¿Hasta qué punto, las "competencias lectoras" son los mecanismos para el blo-queo del "lector competente"?

En la Sociedad de los poetas muertos, una película del año 1989 dirigida por Peter Weir, con guion de Tom Schumann y protagonizada por Robín Williams, narra el encuentro de un profesor de literatura con un grupo de alumnos durante 1959 en la Welton Academy. En la primera clase leen la introducción a la lectura de la poesía. Se trata de una prescripción para calcular el puntaje y la grandeza de una creación poética. El estudiante lee en voz alta:

Para entender la poesía, primero debemos familiarizarnos con su ritmo, métrica y figuras retoricas. Luego debemos hacernos dos preguntas: ¿con cuanto talento se ha conseguido el objetivo del poema? ¿Qué importancia tiene dicho objetivo? La pregunta uno mide la perfección del poema. La pregunta dos, su importancia. Si es-tas preguntas están contestadas, determinar su grandeza, representará una tarea relativamente fácil. (1999).

Terminada la lectura, el profesor les manda a arrancar la página ante la mirada atónita de los estudiantes, ino pueden creer que les toque romper literalmente la regla y el formato que la contiene! ¿Qué queda después de la regla cuando la norma ha quedado atrás?, pa-recen preguntar sus ojos estupefactos. El maestro se adelanta y los convoca a una em-presa: "ahora aprenderán a saborear las palabras sin lenguaje. Las ideas y las palabras pueden cambiar el mundo" (1999).

Mediante el ejercicio táctico del maestro, la lectura de la poesía ha pasado, de la función estratégica de la prescripción, a la acción táctica, de la experiencia. La lectura se hace activa, la lectura se abre a la creación de mundos. El maestro inscribe al lector en otro proyecto, abre la ventana de la experiencia: a partir de ahora no se tratará de que un sujeto pase por la lectura, sino de que la lectura pase por el sujeto; nos hemos instalado en el campo de la subjetividad, de la afectación, de la experiencia de sí, de la lectura activa y activadora de mundo. Le corresponderá a cada uno, a cada uno preguntarse si acepta esta nueva convocatoria, si se abre paso a la fiesta de la experiencia. Este proyecto al cual incita el maestro, solo se hará trayecto si ellas y ellos se ponen en camino de la experien-cia, si se hacen caminantes, si se arriesgan a experimentar.

La lectura es, entonces, una actividad donde $\mathrm{s}$ corre riesgos. Se hereda una cultura, se accede a una cultura, se interviene la cultura heredada, en la lectura toda cultura entra en un proceso de revuelta, supremo combate de los sentidos, otros comienzos. Podemos de-cir, que leer se convierte en el antídoto de una educación que se resiste a cambiar. Los profesores de literatura, y también de filosofía, se sienten muchas veces postergados, por-que la innovación que se le pide a la sociedad se la hace depender de la ciencia y la tecno-logía. Pero lo profesores de literatura, y también los de filosofía, no pueden dejarse rezagar por estas visiones parciales del mundo. Todo cambio estructural de la técnica solo se hace un espacio humanamente habitable si está acompañado de una forma de entender el mundo como un ecosistema donde los sujetos innovadores renuevan la forma de inter-cambiar lenguajes y construir narraciones de estar juntos. 


\section{LEER LIBROS Y LEER EL MUNDO: EL OFICIO DE LA ESCUELA EN LA MEDIACIÓN DE LA LECTURA}

Paulo Freire en Pedagogía del Oprimido (2005), inauguraba un concepto, que marcaría la forma de "leer" la educación, la pedagogía y la didáctica del lenguaje. Nos referimos al concepto de "Pedagogía del oprimido" como una herramienta critica para detectar las prácticas de la educación bancaria. Este tipo de educación se limitaría a transmitir datos como un banco, a transportar información sin que afecte para nada a los sujetos que lo transmiten y que lo reciben. Este tipo de educación legitima una pedagogía del opresor, mantiene oprimidos a los educandos, hace perpetua la opresión. En este estado, los opri-midos carecen de mundo propio, afectándose de manera directa la formación crítica de subjetividad. Se necesita una pedagogía que le permita al educando decir su mundo.

Freire instala una concepción problematizadora de la relación pedagógica, al detectar la contradicción educador-educando. Al mismo tiempo ofrece un modo de superación de esta contradicción mediante el ejercicio mediador del lenguaje, señalando el carácter dia-lógico de la educación como práctica de la libertad.

Toda enseñanza de la literatura en el aula se convierte en un saber pedagógico que se abre a una lectura del mudo. Dice Freire (2005) que deberían darse dos momentos en el acto de leer: un primer momento es la "lectura del mundo"; o como dice Freire, "del pe-queño mundo en que me movía", después un segundo momento, "la lectura de la palabra" (p. 95). Con frecuencia la escuela exige determinados autores y obras para lograr que los estudiantes se hagan lectores, pero olvidan algo importante, que le sirva para leer su mun-do. Freire se lamenta, "la lectura de la palabra, no siempre fue, a lo largo de mi escolariza-ción lectura de la palabra-mundo" (p. 95). El autor recuerda la experiencia vivida, cuando todavía no leía textos: "la vieja casa, sus cuartos, su corredor, su sótano, su terraza -el lugar de las flores de mi madre-, la amplia quinta donde se hallaba, todo eso fue mi primer mundo [...] como el mundo de mis primeras lecturas" (p. 95).

La educación bancaria es una forma de subjetividad política, pero es una subjetividad de tipo opresor donde el mundo del oprimido es el mis- mo mundo del opresor. En cambio, en una educación liberadora, los educandos leen su mundo, la subjetividad política sería, la de los oprimidos. Por tanto, la subjetividad política liberadora tendría que ver precisamente con la capacidad de los sujetos de producir su propia lectura del mundo y apropiarse de él.

Desde esta perspectiva, la subjetividad política sería el poder (política) de ser sujetos (sub-jetividad). Y este poder tendría que ver con la capacidad de apropiarse del mundo en que vive, esta apropiación la llama Paulo Freire, la capacidad de decir su mundo, es el proceso de concientización. En el libro La importancia de leer y el proceso de liberación (2005) Freire recalca que la lectura del mundo es primero que la lectura de los libros y que si se leen los libros es porque primero se ha leído el mundo. Aquí articula, entonces, la subjetivi-dad política con los procesos de lectura.

Después cuando fue profesor de portugués, cuando tenía veinte años sus estudiantes no tenían que memorizar ciegamente la sintaxis, sino que "se proponía a la curiosidad de los alumnos de manera dinámica y viva, en el cuerpo mismo de los textos, ya de autores que estudiábamos, ya de ellos mismos, como objetos a desvelar y no como algo parado cuyo perfil yo describiese" (p. 101).

Me refiero a que la lectura del mundo precede siempre a la lectura de la palabra y la lectura de esta implica la continuidad de la lectura de aquel. [...] Este movimiento del mundo a la palabra y de la palabra al mundo está siempre presente. Movimiento en que la palabra dicha fluye del mundo mismo a través de la lectura que de él ha-cemos. De alguna manera, sin embargo, podemos ir más lejos y decir que la lectu-ra de la palabra no es solo precedida por la lectura del mundo, sino por cierta forma de "escribirlo" o "reescribirlo", es decir, de transformarlo a través de nuestra prácti-ca consciente. (p. 106)

En el texto que mencionamos, se acentúa la lectura y la escritura como acto de subjetivi-dad política, siempre vio en ellos "un acto político y un acto de conocimiento, y por eso mismo como un acto creador" (p. 104). El trabajo del educador es importante como en toda relación pedagógica, no anula la creatividad, se apropia de "su responsabilidad en la creación de su lenguaje escrito y 
en la lectura de ese lenguaje" (p. 104). No se limita a "ir llenando cabezas vacías" sino que se hace de cada educando un sujeto; alguien capaz "de su tarea creadora" (p. 105).

Freire (2005) en La importancia del acto de leer y el proceso de liberación. Presenta su perspectiva sobre la lectura y el impacto que tiene en el desarrollo del ser humano. En este texto académico cargado de una fuerte connotación emotiva, destaca el componente críti-co de la lectura, el cual va más allá de la decodificación de un sistema simbólico para po-nerlo como el acto de leer el mundo, antes que ser un proceso mecánico, es el disfrute del entorno y del aprender el vocabulario desde las percepciones más íntimas que forman el mundo cercano del niño cuando este se acerca por primera vez al lenguaje y su expresión dentro de las normas establecidas.

La lectura del mundo, es el primer acercamiento de los sujetos a la lectura, la cual debe ser una interrelación íntima entre el contexto y el texto, que conlleve al deleite y a la expresión de sus mundos juveniles. Se destaca el hecho de que las creencias, valores, costumbres, imaginarios, gustos, sentimientos y emociones de los individuos se vuelcan al análisis de un texto cuando se entra en contacto con este para ser leído y desmenuzado para su co-nocimiento; es por ello, que la lectura supera el proceso repetitivo para convertirse en un proceso de apropiación en el que se debe hacer evidente el sentir y pensar del sujeto, más aún en la escuela que debe fomentar la actitud crítica para no limitarse a que los estudian-tes lean y digan lo que se espera, lo que se pretende es indagar en ese mundo oculto para descubrir las necesidades e interese reales, para hacer del aprendizaje y la formación un camino de transformación que invite al cambio social.

Permitir experiencias gratificantes de lectura en los sujetos implica un recrear y revivir el mundo a través de la palabra como lo plantea Freire, pues al eliminar este aspecto subjeti-vo, la lectura se torna monótona y pierde el sentido de empoderamiento y reivindicación de las experiencias para alcanzar significaciones profundas de lo que se descubre y aprende, de tal manera, que las ideas queden fijadas y no meramente memorizadas. Se requiere que el conocimiento a través de la lectura se enraíce a través de la experiencia para ser anclado y re- cuperado con facilidad mediante relaciones de pensamiento significativas, por lo que podemos aludir a las palabras del autor en relación con esta y su intrínseca unión con la alfabetización como liberación "[...] Siempre vi la alfabetización de adultos como un acto político y como un acto de conocimiento, y por eso mismo como un acto creador" (p. 104).

Se destaca que la lectura y la alfabetización como actos liberadores del sujeto, no están desligados de la escuela, por el contrario, es el maestro el vehículo, el facilitador de este proceso en el que se propende por la creatividad y, hasta cierto punto como lo afirma Gianni Rodari la fantasía (1999), para enriquecer la expresión escrita y oral en la que se plasme la postura crítica de los sujetos frente a su entorno como individuos políticos y cul-turales autónomos. La subjetividad se hace evidente a través de la lectura crítica de la realidad convirtiéndose como lo afirma Freire en una herramienta para reescribir el mundo, comprenderlo y transformarlo.

Es esencial rescatar de las ideas del autor que la lectura del mundo implica que los sujetos se apropien de su capacidad de asombro, de descubrir el mundo y pronunciarlo a través de la palabra para que conozcan su entorno y sean capaces de cambiarlo a través de ac-ciones claras que alcancen mediante la educación, pues alejarse de la mecanización del conocimiento conlleva al empoderamiento y asumir posturas críticas que evidencian la reflexión sobre las propias actuaciones.

El auténtico acto de leer es un proceso dialéctico que sintetiza la relación existente entre conocimiento-transformación del mundo y conocimiento-transformación de nosotros mismos. Leer es pronunciar el mundo, es el acto que permite al hombre y a la mujer tomar distancia de su práctica (codificarla) para conocerla críticamente, volviendo a ella para transformarla y transformare a sí mismo. (p. 17)

Algunas prácticas de lectura en el aula, y muchas enseñanzas de la literatura, olvidan el punto fundamental de educación literaria, que los estudiantes aprendan a decir su mundo, y encuentren los modos de transformar los entornos en que viven. 


\section{ENFOQUE METODOLÓGICO: LO CUALITATIVO, LO ETNOGRÁFICO Y LO HERMENÉUTICO}

La propuesta se enmarca en una metodología cualitativa en un campo investigativo que articula la etnografía, el enfoque hermenéutico con recursos propios de estas investigacio-nes como la observación participante, la entrevista no estructurada, y la interpretación de la realidad. En ellas se advierte una interacción entre el investigador y los participantes. En este sentido, permiten que el trabajo en un contexto escolar, especialmente en un aula de clase, pueda comprender las relaciones entre el sujeto y su comprensión del entorno al que pertenece.

Como lo afirma Irene Vasilachis (2009), investigadora argentina, citando a Mason (1996) en su texto Estrategias de la investigación cualitativa la "concepciones acerca de la reali-dad y acerca de cómo conocerla y de cuánto de ella puede ser conocido determina que no pueda afirmarse ni que haya una sola forma legítima de hacer investigación cualitativa ni una única posición"(p. 24); es por ello que este proyecto se apoya en dos enfoques: la observación participante para utilizar las herramientas adecuadas dentro del campo inves-tigativo y la hermenéutica que permite una interpretación de los datos obtenidos a partir de las herramientas utilizadas, esto para dar al trabajo una descripción pertinente de los ha-llazgos obtenidos.

La dinámica del método cualitativo, continuando con Vasilachis (2009), está orientada por fundamentos epistemológicos y de construcciones de teoría de la ciencia: "La investigación cualitativa está fundada en una posición filosófica que es ampliamente interpretativa en el sentido de que se interesa en las formas en las que el mundo social es interpretado, com-prendido, experimentado y producido" (p.25). En nuestra investigación se busca interpretar el mundo de los jóvenes, las vivencias de las prácticas escolares, conocer a los estudian-tes, participar con ellos y allí percibir como construyen sus mundos y proyectan su vida.

Vasilachis aporta el concepto de que la investigación cualitativa parte de una epistemología del sujeto conocido. En efecto, ella establece la distinción entre una epistemología del suje-to cognoscente y una epistemología del sujeto conocido que, en las investigaciones de cor-te positivo suelen permanecer aisladas. La epistemología cognoscente se centra en un sujeto con fundamentos, epistemológicos abstractos válidos para todo contexto. De esta manera, el sujeto cognoscente se considera fundamento del conocimiento y debe tomar distancia de los sujetos que conoce para asegurar la "objetividad". En cambio, la epistemología del sujeto conocido, plantea la necesidad de recuperar la voz y las condiciones histó-ricas, el contexto y el mundo en el que vive el sujeto conocido; de esta manera se puede construir la fuente del conocimiento de la población.

La investigación se centra también en el enfoque hermenéutico ontológico político como lo proponen los investigadores Sara Victoria Alvarado, Ariel Gómez, Maria Camila Ospina y Héctor Fabio Ospina en su artículo La hermenéutica ontológica política o hermenéutica performativa: una propuesta epistémica y metodológica (Abril, 2014). Se trata de una acti-tud para transformar el mundo de los sujetos a partir de su interpretación cotidiana y su afectación:

De la obra del filósofo alemán Martin Heidegger retoma la hermenéutica ontológica, en tanto a partir de ésta se manifiesta más que un método investigativo, un camino, un horizonte que va en busca de comprender los diversos modos como los huma-nos nos disponemos a habitar y construir el mundo. Una hermenéutica así, propone "recuperar, a partir del mundo cotidiano y de la cosa misma, el modo de ser de los textos estéticos, humanos y sociales; además, de la acción cotidiana elocuente como campo de comprensión" (Botero, 2005 [2000]: 32); añade a la hermenéutica ontológica heideggeriana una perspectiva política, un sujeto con capacidad de ac-ción, esto es, capacidad para introducir algo nuevo, para crear mundo e inaugurar algo con consecuencias impredecibles e inesperadas. (p. 212)

Es importante destacar que se recurre a la experiencia de los sujetos como herramienta de participación e interpretación para llegar a una transformación de los fenómenos sociales en los cuales se evidencien la tensión de poder/ dominación y se hagan presentes aquellas voces y discursos que han sido acallados en esta dinámica de interacción social. 
Para esta propuesta hermenéutica ontológica existen tres elementos constitutivos de esta interpretación: el lenguaje, el pensamiento y la acción. "El lenguaje, da cuenta del modo subjetivo con que habitamos el mundo, asimismo, permite dar cuenta de cómo vamos construyendo intersubjetivamente la historia” (p. 212).

El pensamiento nos hace críticos frente a las verdades admitidas, "Pensamiento es posibi-lidad de interpelar la historia, confrontar estructuras $\mathrm{y}$ verdades que parecen inamovibles y absolutas (p. 212). Finalmente, la hermenéutica ontológica, es transformadora, es acción: "Nos habla de la posibilidad que tenemos los seres humanos para construir historia, para producir la realidad a través de encuentros y desencuentros que se experimentan en la esfera pública del "entre nos" (p. 213).

La hermenéutica por sus condiciones propias de interpretación de las vivencias y actua-ciones de los sujetos se convierte en un escenario propicio para hacer visible la subjetivi-dad especialmente, cuando hablamos de subjetividad política, pues, nos permite "leer el mundo" (Freire, 1985) que se oculta en las actuaciones cotidianas y le permite a su vez a los participantes leer-se a través del mundo, garantizando al investigador "un aporte políti-co a la comprensión y transformación de lo social" (Alvarado, Ospina-Alvarado, SánchezLeón, 2016, p. 988)

\section{Herramientas para la Recolección DE DATOS.}

La etnografía es un método de investigación ampliamente explicado por la investigadora Rosana Guber en su texto la etnografía. Método, campo y reflexibilidad (2001). Ella propone dos herramientas para la recolección de datos: la observación participante y la entrevista no estructurada. Con ellas se trata de abandonar la idea de población a estudiar y más bien hacerlos participes de la investigación. Con su noción de "informantes" busca superar las barreras epistemológicas de la construcción de las comunidades como "objeto" de es-tudio.

\section{ObSERVACIÓn PaRTICIPANTE Y LA REFLEXIVIDAD}

No se trataría de observación como cuando un científico observa un objeto de la naturale-za, si fuera así, dicha observación "ubicaría al investigador fuera de la sociedad para reali-zar su descripción" (Guber, 2001, p.57); sería un momento donde los datos logran ser da-dos desde una parte exterior del contexto que resulta ser un fuera imaginario.

Se trata más bien de "observación participante": "La participación pone el énfasis en la experiencia vivida por el investigador apuntando su objetivo a "estar dentro" (Guber, 2001, p. 57) Cada uno de los factores que conforma esta herramienta cumple un papel importante a la hora de la práctica en el trabajo de campo.

La observación conlleva a dar testimonio de lo vivido de lo experimentado, transmite a otros lo que sucede dentro de la comunidad que observó; la participación por su parte, ha-ce referencia a la subjetividad que lleva al investigador a la comprensión de las prácticas en las cuales está involucrado durante la investigación. Esta técnica de recolección no ofrece ninguna transformación para la comunidad a la cual se le realiza la investigación, pero si ofrece a una apropiación y experiencia a quien la lleva a cabo. Esa experiencia está orientada en la reflexibilidad.

Para Guber (2001) "La reflexibilidad señala la íntima relación entre la comprensión y la expresión de dicha comprensión" (p. 46) esta íntima relación permite describir lo sucedido en el campo de trabajo durante la observación participante todo esto, desde la experiencia.

\section{LA ENTREVISTA NO ESTRUCTURADA:}

Según Guber (2001), "La entrevista es una situación cara a cara donde se encuentran dis-tintas reflexividades, pero, también donde se produce una reflexibilidad" (p. 76). En ella las preguntas permiten responder asuntos puntuales, pero al mismo tiempo es abierta para entrar en una conversación sobre el sentido del tema que estamos tratando. Se puede ha-cer preguntas donde el entrevistado de explicaciones o controvierta la pregunta. Este es un punto importante de la reflexividad de la entrevista no estructurada.

\section{ANÁLISIS DE RESULTADOS. EL "MUNDO" QUE LOS JÓVENES "DICEN"}

La intencionalidad que ha movido el presente proyecto de grado es establecer la relación 
entre lectura literaria y subjetividad política en estudiantes de educación media. ¿Bajo qué condiciones la lectura literaria permitiría a los jóvenes estudiantes de educación media "decir su mundo" como una expresión de su subjetividad política?

Cuando hablamos de condiciones nos estamos refiriendo a unas características de orden educativo, personal, contextual que, si no se dan, hacen de la enseñanza de la literatura un momento sin sentido para los estudiantes. AM Chartier (2014), por ejemplo, señala que cuando se utiliza la lectura como acceso a una cultura mejor que la de los estudiantes, la enseñanza se convierte en algo tedioso, conociendo autores que no les dice nada. La auto-ra a lo largo de todo su trabajo habla de la importancia de las lecturas conversadas: aquellas lecturas que a los estudiantes motivan o los conectan con lo que viven.

Digamos primero, que las condiciones que no permiten el desarrollo de una subjetividad política son las lecturas obligatorias, las lecturas descontextualizadas, las lecturas no conversadas.

Buscamos, entonces, unas condiciones de orden formativo, pedagógico que averigua so-bre la posibilidad de expresar con la literatura una postura crítica frente al mundo que le rodea, frente a lo que les pasa y frente a lo que esperan en sus vidas. Por eso la pregunta, ¿̇ajo qué condiciones la lectura literaria permitiría a los jóvenes estudiantes de educación media "decir su mundo" como una expresión de su subjetividad política?

Esta pregunta nos llevó por tres preguntas específicas que avadaron, cada una:

- Cómo expresan los jóvenes una lectura de su mundo: lo que los afecta, lo que bus-can, lo que quieren ser, sus anhelos, sentimientos, frustraciones. Se trató de un via-je por el mundo interior juvenil.

- De qué manera se identifica la afectación que producen en los jóvenes las lecturas literarias cuando la abordan imaginativamente. Se trató de una oportunidad de es-tablecer la relación afectación y lectura literaria.

$\mathrm{Y}$, finalmente buscamos,

- Describir los procesos de creación de los jóvenes a través de la producción escrita, para establecer la relación creación y mundo juvenil.
Vamos a desarrollar cada uno de estos aspectos:

\section{¿Se PUede el AULA COMUNICAR CON EL MUNDO JOVEN?}

Una condición que hallamos, es que la literatura debe recomponer una relación perdida, la relación pedagógica. Una de las advertencias de Gabriel Kaplún es que la comunicación con los jóvenes se haya en una gran crisis. En su libro ¿Educar ya fue? culturas juveniles y educación (2008) nos hace caer en cuenta que toda relación de autoridad se ha roto y que la conversación se hace imposible. Sin embargo, esta constatación nos lleva precisa-mente a recomponer la conversación, a curar el puente que se ha quebrado.

¿Cuál sería la condición de esta recomposición? ¿Cómo iniciar el dialogo? Para que la educación vuelva a ser posible necesitamos aceptar los modos como los jóvenes expresan su mundo, o sea, entrar a través de la dimensión estética: sus expresiones corporales, su música, sus símbolos. Eso fue lo que buscamos en este trabajo a través del identikit y el audio disparador.

Tres asuntos que les preocupa aparecieron en las actividades,

- La preocupación por el futuro. (proyecto de vida)

- La construcción de la identidad.

- Y sus aficiones cotidianas

Los jóvenes al estar en su último curso de educación media les preocupan qué pasará con su futuro. En la conversación que se tuvo con ellos se reflejaba un interés en saber sobre cómo se lleva a cabo la vida para una persona que estudia, trabaja y tiene un hogar; ese mundo profesional les interesaba.

Los jóvenes saben que su futuro depende de una formación académica, sin embargo, du-rante las otras actividades con ellos se escucharon opiniones enfocadas en como a partir de sus aficiones como por ejemplo ser un Gamer también se puede obtener ingresos eco-nómicos y a la vez hacer lo que les gusta, en otros casos, la preocupación por el futuro está centrada en ayudar a otras personas esto, se reflejó en el ejercicio de la construcción biográfica donde, una joven expresa que quiere ser doctora para ofrecer ayuda desde 
su profesión en su enfermedad. Esto muestra que los jóvenes sienten preocupación por el futuro y desean construir un proyecto de vida pero que ese proyecto no está orientado es-pecialmente en ser un profesional y cumplir con el requisito de haberlo sido, sus posturas están claras quieren ser lo que ellos consideran que deben ser, ven la posibilidad de cum-plir con una exigencia social, pero desde lo que les apasiona lo que por ahora les interesa. Preocupación por el futuro para los jóvenes de la IED La floresta sur es poder empalmar sus aficiones, sus gustos con la posibilidad de que ello les dé una posición y una forma de solventar sus necesidades económicas

Los jóvenes en sus producciones estéticas muestran con qué actividades y aficiones cons-truyen su mundo juvenil. En este ejemplo se puede observar como este joven se identifica con el futbol, la música, el comic. Cada identikit se abre a la posibilidad de una lectura del mundo del joven.

Por medio de estas construcciones estéticas se puede crear una relación entre los jóvenes y los adultos. Dentro del mundo escolar se encuentra una variedad de mundos, diferentes construcciones; se busca a partir de la formación escolar ofrecer saberes que les permita a los muchachos construir su mundo social.

La música, sus deportes favoritos al igual que sus programas de televisión son unas de las aficiones que predominaron en los modos como los jóvenes construyen su mundo. Ellos lo expresan no solo en los identikits, también en los otros ejercicios que se trabajó en el aula de clase. Si tuvimos la "generación de la guayaba "y los "milenian", ahora estamos asis-tiendo a una nueva generación: los netflix: el cine en casa. Los afectos cercanos son su mascota. ¿Y los demás miembros de la familia? Hay una construcción de identidad que no referencia sus vínculos familiares. Hay que hablar de esto con ellos.

\section{EL MENSAJE QUE VIENE DE LA OTRA ORILLA: LOS JÓVENES}

Otra condición para la enseñanza de la literatura es que produzca afectación, es decir otras miradas de sí mismo y del mundo que les rodea. Una de las convicciones que mueven este trabajo es la afirmación de Freire la lectura del mundo es primero que la lectura de obras literarias; y que si las lecturas de obras literarias son importantes es porque están acompañadas de una lectura del mundo.

Hay una afirmación muy común de que a los muchachos nos les gusta leer y menos es-cribir. Pero el trabajo con ellos se notó todo lo contrario; ellos hablan, leen o escriben de lo que lo afecta, y este es el punto para iniciar una conversación formativa con ellos. Los jó-venes construyeron autobiografías en donde se expresaban dos aspectos,

- vínculos afectivos (familia, amigos y noviazgo)

- mundo interior (frustraciones, alegrías, expectativas y búsquedas)

En los ejercicios de construcción narrativa que se realizaron en el aula de clase, ellos deja-ron ver sus vínculos afectivos como: la amistad, el noviazgo y las relaciones con la familia. Las construcciones narrativas permitieron leer estas relaciones de los jóvenes y cómo construyen sus mundos. Al momento de conversar con ellos sobre el ejercicio realizado hubo un hermetismo, no hablaron del tema. Esto muestra como la escuela no toma en cuenta estos vínculos como posibilitadores de una conversación

Diera la impresión que lo afectivo se queda por fuera del aula, por fuera de la escuela. La literatura podría crear el espacio para que vuelvan las emociones, los sentimientos que los planes de estudio dejan por fuera. Podría construirse con ellos unos modos que permita que los vínculos, las relaciones sean reconocidos como constructores de subjetividad. La literatura construye estos vínculos y le permite al lector recrearlos y vivirlos; a partir de ellos los maestros podrían trabajar con los jóvenes en la formación para la vida.

Sería pertinente construir con los jóvenes ejercicios que retomen estas relaciones como un acto de reconocimiento propio y que ellos reconozcan que a partir de ellos cada sujeto se construye y se forma y otros se forman con ellos, este es el papel de la educación Los jóvenes están haciendo un llamado a la escuela, a sus saberes y sería pertinente que esta acuda a ese encuentro y por qué no desde los saberes que imparte en este caso la lectura literaria 
Es sorprendente ver como los jóvenes que participaron en los ejercicios no acuden a las lecturas obligatorias de la escuela, pero si acuden a sus encuentros con amistad. ¿Acaso la lectura literaria no refleja la amistad? ¿O será Qué a la lectura literaria dentro del aula de clase no permite que los jóvenes muestren sus vínculos afectivos? Quizás esto explica el por qué ellos acuden a sus propias lecturas, para imaginar y recrear esos mundos donde se encuentran inmersos.

\section{LEER EN VOZ ALTA: LEER PARA JUNTARSE CON OTROS}

Otra condición de la lectura para la producción de la subjetividad política es permitir su es-pacio creativo, permitir la espontaneidad. Es un hecho que los estudiantes escriben. Pero los estudiantes no solo escriben, también leen, leen de otro modo y leen a su manera.; se halló en esta investigación que a la juventud le gusta que les lean. En la entrevista no es-tructurada, los estudiantes nos contaron sobre sus gustos y aficiones en literatura, los for-matos que prefieren y los espacios que escogen para leer y dejaron ver, la forma como disfrutan la lectura en voz alta.

Transcribimos a continuación una conversación que surge después de haberles leído a los estudiantes un libro álbum.

Profesora: cada uno quiere tener la razón y por eso se da la violencia. Pero hay una cosa importante que tiene que ver con la comunicación. En el cuento hay un tercero que es la forma de resolver. ¿Cuál fue el problema de ellos? Estudiantes: la comunicación, no se escucharon, no se pusieron de acuerdo.

Profesora: ¿qué es lo que nosotros hacemos todo el tiempo?

Estudiantes: reproducimos los conflictos

Profesora: ¿Qué será eso que ustedes como estudiantes de once que van a em-pezar a ser ciudadanos activos deben reconocer?

Estudiantes: La responsabilidad

Profesora: ¿y qué es responsabilidad?

Estudiantes: hacerse cargo de uno mismo

Se muestran interesados en el tema de la relación violencia y comunicación. La lectura en voz alta produce mucho interés en ellos. ¿Será que la lectura en voz alta produce algún recuerdo de protección, de matriz maternal, o algo así?
La lectura puede ser por sí mismo, acto poético, como lo antiguos llamaban todo acto de creación. Y es acto estético, pues es el momento de la invención de sí mismo. Así lo expresa el autor de la educación como práctica de la libertad: "Pensábamos en una alfabetización que fuese en si un acto de creación, capaz de desencadenar otros actos creadores" (Freire, 1967, p. 164). La lectura es obra, permite imaginar, comparar, reflexionar, recom-poner. Se hizo con los muchachos un ejercicio de lectura en voz alta donde, ni ellos espe-raban encontrar lo que hallaron. Algunos no imaginaron que en un libro álbum como alguno lo denominó "un libro para niños" encontraría quizás parte de lo que viven.

En aquella lectura espontanea ellos y ellas lograron identificar por si solos valores, vínculos afectivos de los que se habló anteriormente, relaciones que a diario vivimos y se pasa desapercibida es decir, la relación entre el hombre y los animales, la relación con la natura-leza. Cada uno de los participantes del ejercicio de lectura en voz alta vivió su propia expe-riencia y a partir de ella participo e intervino.

Con esta dinámica se rompió la idea de que los estudiantes no prestan atención en clase, que no participan, y sobre todo que no les gusta leer o que les lean. Con esta participación quedo de lado el imaginario que los jóvenes tiene de la "lectura infantil" con exclusividad para una edad especifica. Y si es así, entonces ¿Se podría entender que la lectura infantil en voz alta despierta en ellos un recuerdo de su infancia?

Este ejercicio propone herramientas para construir dentro del aula de clase espacios para romper con imaginarios y que conlleven a la reflexión tanto del maestro como del alumno.

\section{LO QUE PUEDE UN LIBRO SOBRE EL PUPITRE}

Los estudiantes aún tienen la casa como lugar de estudio. Por qué hay condiciones familia-res: silencio, tranquilidad, comodidad, atención de sus padres. Este punto sería pertinente conversarlo con los padres de familia para seguirlo cultivando: que los muchachos prefie-ran su casa, quiere decir que no se ha perdido aún y que todavía se puede trabajar cierta complicidad.

Para los jóvenes la lectura de libros es preferida pues consideran que al momento de leer en 
este formato la imaginación está presente en lo que van leyendo. Leer en los libros de acuerdo a lo que argumentan los jóvenes, también les permite subrayar siendo esta una posibilidad para ellos de entender lo que se habla en el libro. Otra argumentación de los jóvenes es que le prestan más atención a la lectura en libro.

Los estudiantes leen en jornada contraria, lo hacen menos los fines de semana (más dedi-cado a amistades y diversión). La casa está más sola en la jornada contraria, no pasa lo mismo en los fines de semana. Esto coincide: los estudiantes estudian en jornada contraria porque aun lo pueden hacer en un sitio que les resulta acogedor y productivo para sus fines.

Los estudiantes prefieren los relatos que atiendan sus problemas juveniles: en la conversa-ción aclararon que se trata de autores que hablan de conocimiento de jóvenes: en realidad los estudiantes entienden por relato juvenil, no el género literario, sino las temáticas que abarcan: autoayuda, asuntos emocionales.

Los estudiantes prefieren leer solos. De pronto se trata del disfrute de la lectura a solas. Si se trata de lectura que atienden problemas personales, ciertamente lo prefieren atender en solitario. Y si se trata de lectura obligatoria, prefieren la concentración.

Los libros en los jóvenes aun aparecen como compañía. La afirmación de que a los jóve-nes no les gusta leer, parece desmentida aquí. También la idean de que las tecnologías desplazaron el texto escrito tampoco tiene como sostenerse con esta investigación.

Los relatos preferidos son los de ficción y le siguen los fantásticos y mitológicos; esto posi-blemente a la ayuda del cine. El fantástico atiende también las necesidades de acción. Las románticas las prefieren las niñas; aunque hay niñas que buscan también los fantásticos y de ficción: los gustos se están emparejando por géneros.

Los estudiantes expresan preferencia por el texto impreso. Esto debido a la facilidad de manipulación, el poder subrayar y su transporte. Dejan las tecnologías para otras activida-des. Las películas ocupan un segundo lugar, pero con buen porcentaje y lo mismo el co-mic. Esto nos lleva a pensar en la necesidad de emprender una educación sobre la impor-tancia del cine como formación y del Comic como género literario: es una tarea pendiente.

La lectura obligatoria la prefieren atender en solitario y en silencio. Creen mucho en la con-centración y en la intimidad de la lectura. Este es un aspecto interesante: lo mismos estu-diantes creen en el rigor de la lectura. Este punto hay que explotarlo; aún existe un com-promiso con la lectura y su exigencia de concentración.

La literatura en la escuela y el ejercicio lector en el aula pone en camino el acontecimien-to pedagógico que se puede ofrecer a los jóvenes y a las jóvenes, como herencia determinante, la invención de otra humanidad. Ni las nuevas tecnologías, ni el saber libresco, lo hacen por sí mismos. La humanidad no se transmite, la humanidad se contagia, está hecha de cuerpos que se encuentran, que se escuchan, que se contrarían, que negocian y se colaboran. En la clase de literatura nos queda "dar de leer", proponer la lectura del deseo para que emerja el deseo de lectura. En este punto, Fernando Savater, invita a los maes-tros, a poner libros sobre el pupitre:

Lo ha diagnosticado muy bien Gianni Rodari en su simpática Gramática de la Fan-tasía: "El encuentro decisivo entre los chicos y los libros se produce en los pupitres del Colegio. Si se produce en una situación creativa, donde cuenta la vida y no el ejercicio, podrá surgir ese gusto por la lectura con el cual no se nace, porque no es un instinto. Si se produce una situación burocrática, si al libro se le maltrata como instrumento de ejercitaciones (copias, resúmenes, análisis gramatical, etc.) sofo-cado por el mecanismo tradicional examen-juicio podrá nacer la técnica de la lectu-ra, pero no el gusto.” (1997).

Estamos jugándonos el encuentro decisivo. Frente a las estrategias de unas competencias lectoras, la escuela responde con los juegos tácticos de la producción de sentido. No se trata ya de oponer tecnologías y libro, videos juegos o lectura, sino de introducir el acontecimiento de la inquietud, del cultivo de la propia valía, de hacer de la lectura lucha por ha-cerse reconocer, de oportunidad de salir de la cultura del silencio, en la que no ubica cier-tas prácticas de dominación. Leer se convierte en la desinstalación de la cultura dominan-te, de los medios, de las modas, del entretenimiento. Leer se convierte en riesgo y respon-sabilidad pues se abre la paciente labor de darle forma a la impaciente libertad 
Referencias bibliográficas

Alvarado, S. A., Ospina-Alvarado, M. C. y Sánchez-León, M. C. (julio - diciembre de 2016). Hermenéutica e Investigación Social: Narrativas generativas de paz, democracia y reconciliación. Revista Latinoamericana de Ciencias Sociales, Niñez y Juventud, 14 (2), pp. 987-999. Recuperado de http://www.redalyc.org/articulo.oa?id=773464560o8

Alvarado, S. A., Gómez, A., Ospina M. Ospina H. (Abril 2014). La Hermenéutica ontológica politica o hermenéutica performativa: una propuesta epistémica y metodológica. Nómadas 40, Universidad Central, Colombia. Recuperado de http://www.redalyc.org/pdf/1051/105131005014.pdf

Ángel, D. A. (diciembre de 2011). La hermenéutica y los métodos de investigación en ciencias sociales. Estudios filosóficos. (44). 9 - 37 .

Anzaldúa, R (2007). Lo ‘imaginario en la Investigación Educativa, Memoria. IX Congreso COMIE, México: http://www. comie.org.mx/congreso/memoriaelectronica/v10/pdf/area_tematica_15/ponencias/o251-F.pdf

Ávila, R. (2010). Reseña: La comprensión de lo social. Horizonte hermenéutico de las ciencias sociales. Universidad Pedagógica: Facultad de Educación. (32), pp. 125 - 132.

Betancur, D. Y Areiza, E. (2013). Tres puertos literarios para volver a los vínculos entre literatura, formación y escuela. Magis, Revista Internacional de Investigación en Educación. 5(11), pp. 441-453. Recuperado de: http:// magisinvestigacioneducacion.javeriana.edu.co/

Briones, G. (1990). La formulación de problemas de investigación social. La formación de docentes en investigación educativa. Módulo 1, la investigación social y educativa. Secretaria ejecutiva del convenio Andrés Bello, Bogotá, Colombia.

Cárcamo, H. (septiembre de 2005). Hermenéutica y análisis cualitativo. Cinta de Moebio. (23), pp. 204 - 216. Recuperado de: www.moebio.uchile.cl/23/carcamo.htm

Cuervo, C. (2015). El círculo de lectura literaria, una experiencia crítica y de afectación con la comunidad. Revista Magisterio. Recuperado de: https://www.magisterio.com.co/articulo/el-circulo-de-lectura-literaria-una-experienciacritica-y-de-afectacion-con-la-comunidad

Cuesta, C. (2006). Discutir sentidos: la lectura literaria en la escuela. Libros del Zorzal. Buenos aires, (Argentina)

Chartier, A. M. (2014). Enseñar a leer y escribir una aproximación a la historia. México D.F., México: Fondo de Cultura Económica.

Freire, P. (1970). Pedagogía del Oprimido. Buenos Aires, Argentina: Siglo de XXI Editores.

Freire, P. (2005). La importancia de leer y el proceso de liberación. Buenos aires, argentina. Siglo XXI editores

Guber, R. (2001). La etnografia. Metodo, campo y reflexivilidad. Bogotá, Colombia. grupo editorial norma.

Herrera, J. D. (2010). La compresión de lo social, Horizonte hermenéutico de las ciencias sociales. Bogotá, Colombia: CINDE.

Herrera, J. D. (2013). Pensar la educación, hacer investigación. Bogotá D.C., Colombia: Universidad de La Salle.

Itatí, R. M. (2012). La formación de la subjetividad política. Recuperado de: http://www.scielo.org.co/pdf/rcde/n63/ n63a19.pdf

Kaplún, G. (2008). ¿Educar ya fue? Culturas juveniles y educación. Montevideo, Uruguay: Nordan comunidad.

Lanz, C. (2012). El cuidado de sí y del otro en lo educativo. Utopías y praxis latinoamericana. 7(56), pp. 39-46. Recuperado de: http://www.redalyc.org/comocitar.oa?id=27921998005

Latorre A. (2005) Investigación-acción Conocer y cambiar la práctica educativa. Barcelona. Editorial Graó.

Larrosa, J. (2013). La experiencia de la lectura estudios sobre literatura y formación. México, D.F. Fondo de cultura económica

Lerner, D. (2001). Leer y escribir en la escuela: lo real, lo posible, y lo necesario. México D.F., México: Fondo de Cultura Económica. 
López, R. A. (2015). Escribir para cuidar de sí y del otro: pensarse, crearse y regirse desde la escritura. Actualidades Pedagógicas. (65), pp. 229-244. Recuperado de: https://revistas.lasalle.edu.co/index.php/ap/article/ download/3491/2772/

Martínez, M. (2006). La investigación cualitativa (síntesis conceptual). Revista IIPSI. 9(23), pp. 123 - 146.

Mayring, P. (junio de 2000). Qualitative Content Analysis. Forum Qualitative Sozialforschung / Forum: Qualitative Social Research. 1(2), art. 20. Recuperado de: http://nbnresolving.de/urn:nbn:de:0114-fqsooo2204

Montañez, M. (2007). Más allá del debate cuantitativo/cualitativo: la necesidad de aplicar metodologías participativas conversacionales. Política y sociedad. 44(1), pp. 13 - 29.

Olivares, S y González, J (2016). La generación Z y los retos del docente. Volumen XI. Los retos de la docencia ante las nuevas características de los estudiantes universitarios. Recuperado de: http://www.ecorfan.org/proceedings/CDU_ XI/PROCEEDING\%20TOMO\%2011.pdf\#page=126

Pennac, D (2001). Como una novela. Barcelona. Anagrama.

Ruedas, M., Ríos, M.M. y Nieves, F. (2009). Hermenéutica: la roca que rompe el espejo. Investigación y posgrado. 24(2), pp. $181-201$.

Savater, F. (1997) El valor de educar. España. Ariel.

Reyes, R. (2002). Investigación pedagógica para la educación religiosa y la pastoral social. Bogotá, Colombia: Pontificia Universidad Javeriana.

Ruiz, A. y Prada, M. (2012). La formación de la Subjetividad Política. Propuesta y recursos para el aula. Buenos Aires, Argentina: Paidós.

Rodari, G. (1999). Gramática de la fantasía: introducción al arte de contar historias. Santafé de Bogotá. Panamericana Editorial

Tassi, E. (agosto de 2012). De la subjetivación política. Althusser/Raciére/ Foucault/Arendt/Deleuze. Revista de Estudios Sociales. (43), pp. 36 - 49. Recuperado de: https://revistas.uniandes.edu.co/doi/pdf/10.7440/res43.2012.04

Torres, A. (enero-junio 2006). Subjetividad y sujeto: Perspectivas para abordar lo social y lo educativo. Revista Colombiana de Educación. (50), pp. 86-103. Recuperado de: http://www.redalyc.org/pdf/4136/413635244005.pdf

Vasilachis G, I (2006) Estrategias de investigación cualitativa. Barcelona. Editorial Gedisa

Zuleta, E. (1982). Sobre la lectura. Recuperado de: https://www.mineducacion.gov.co/cvn/1665/articles-99018_archivo_ pdf.pdf

Secretaria de Educación de Bogotá, (s.f.). Colegio La Floresta Sur (IED). Bogotá D.C., Colombia: Alcaldía mayor de Bogotá. Recuperado de: https://www.educacionbogota.edu.co/media/k2/attachments/COLEGIO_LA_FLORESTA_SUR_IED. pdf

Stead P. C. (2011) Un día diferente para el señor Amos. Madrid España Océano Travesía. 
Revista incluida en los siguientes agregadores de contenidos
Revista incluida en los siguientes directorios

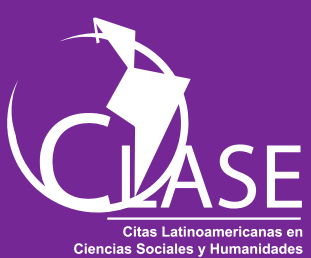

Ullbiblat

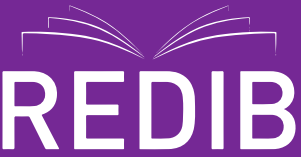

Red Iberoamericana

de Innovación y Conocimiento Cientifico

\section{Google Académico}
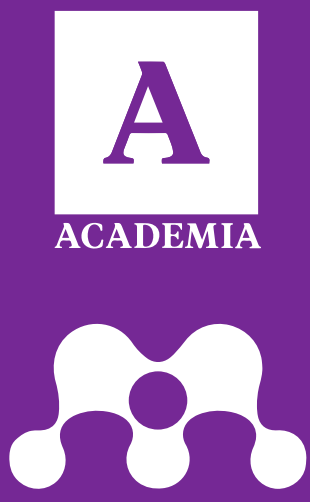

MENDELEY

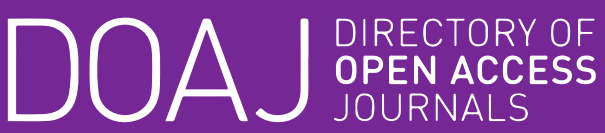

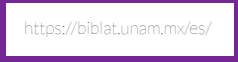
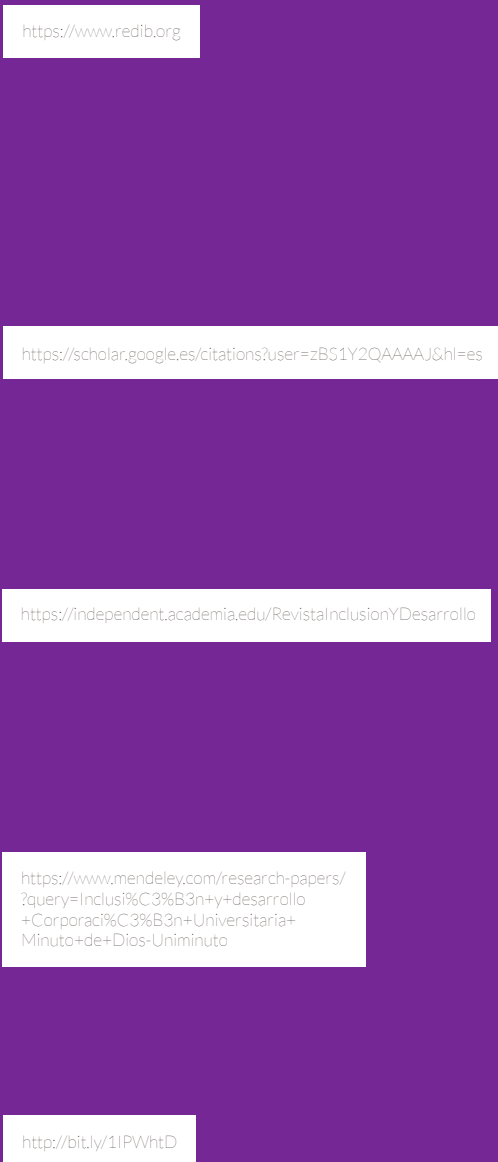

Revista incluida en la siguiente red social

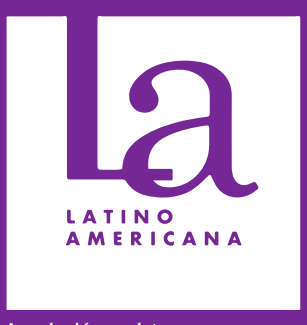



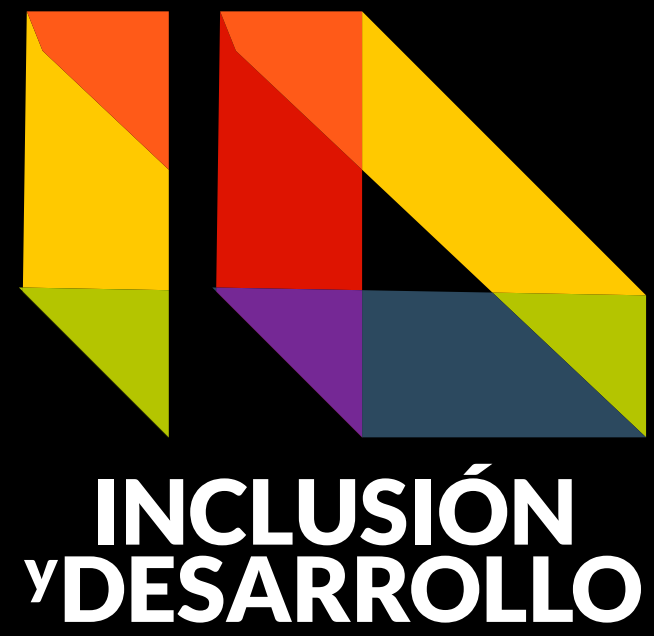

No. 1 Vol. 6 Año 2019 ISSN En línea: 2590-7700

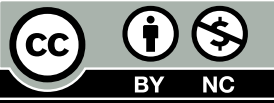

